\title{
Language Learning Generators - From Traditional Language Learning Methodologies to Future Computer Assisted Technologies
}

\author{
Eva Zanuy* $^{*}$ \\ Escoles Betlem, Ramal 1, Premia de Dalt, Barcelona, Spain. \\ * Corresponding author. Tel.: +34 9375110 09; email: evazanuy@hotmail.com \\ Manuscript submitted August 28, 2014; accepted May 28, 2015. \\ doi: 10.17706/ijcce.2016.5.2.158-164
}

\begin{abstract}
Textbooks should are tools that generate learning, and if we improved them taking into account the different learning styles, we would be creating a real Learning Generator for all the students. But the piece of the larger problem I am breaking off to work on is how to choose a Learning Generator or perfect textbook.

The scope of my research includes the bestseller publishing houses in teaching English as a second language (Cambridge, Oxford, Longman, Macmillan and Richmond) and each single exercise in these textbooks will be classified on the basis of Learning Styles. The higher representation of exercises that could help the Reflector Style shows that all the publishing houses, without exception, follow the natural method. The natural method fails because it has an excess of a single Learning Style.

Consequently, the publishing houses have to pay greater attention to the theories on Learning Styles and use learning systems platforms that benefit all the students. This can be accomplished through multimedia education. The future of education is in a virtual world. We should change a system based on books which just benefits a small group of students, to an e-learning system. The application of technology should become normalized moving from classrooms to language labs. Could we imagine a learning system where all students learned at their best?
\end{abstract}

Key words: Computer application, learning styles, second language, teaching methodologies.

\section{Introduction}

The study of learning styles tries to explain the individual differences in the way people use their cognitive resources, learning best depending on the way they both get and process information. When we talk about learning styles we talk about the fact that when we want to learn something each one of us uses our own method of learning or set of strategies. No learning style lasts all our life and is unchangeable, but each one of us tends to develop certain preferences as far as general learning style.

Those tendencies provide our own style of learning. Our learning style would come to be the general tendency, the most used. The learning styles are modified depending on the circumstances, contexts and personal fluctuations of the same student [1]. Consequently, they can be modified for a better advantage. Students will learn how to improve the different styles that they use, and we can help them on it. Of all the theories on learning styles we have, on the one hand, those theories dealing with the information input or Neurolinguistic Programming (NLP) and, on the other hand, the theories about the information process by 
Honey and Munford [2]. Our students have an evident preference for certain learning styles, making obsolete the old system centered on the teacher and in order to make learning effective, each student requires of a style of education adapted to his own way of learning [3].

It also has the additional problem that not all the teachers have much knowledge of that variety and do not know the strategies to follow according to the theories of the Learning Styles and the importance of this investigation is to try to optimize the education and practice of a foreign language, increasing the level of knowledge of all the students using a Learning Generator or common text book for all the students of a specific English level, organizing it previously so that it teaches up to the maximum capacity of each student, considering their learning style and thus eliminating the teaching style of each teacher [4].

The new technology used when teaching, such as computers and digital books, could somehow help students to organize their talents [5]. This way, we would be creating the ultimate teaching tool, a Learning Generator or textbook able to optimize their learning process [6].

\section{Differential Learning}

\subsection{Pedagogical Approach}

Although it may seem excessive, this investigation exceeds expectations since the initial target was only to see which editorial was better in quality, taking into account the diversity of learning styles. The application of a pedagogical approach and the supplementation of the learning programming of a second language must cope with several considerations. In a deductive presentation one begins with axioms, principles or rules. A great percentage of the class is deductive, probably because it is an elegant and efficient way of introducing what it is taught.

Nevertheless, it is obvious that to incorporate an inductive component in education encourages effective learning. Thus, inductive education has to have its place just like the deductive one. Connecting this to the education of second languages, we could say that, at the moment, the deductive method would be the classic one and the inductive one would correspond to the natural method, so fashionable nowadays. For this last one, to acquire a language means a gradual learning, obtaining the ability of communication without the necessity of using the rules that a teacher works with, which could help the students with a dominant Reflector Style, since they are observers, compilers and assimilators.

If we have to balance deduction and induction, the text books used in English language teaching follow a wrong methodology, since they could help a single learning style, the Reflexive one, making learning difficult for students with other learning styles. This happens because the publishing houses follow the natural method. Taking this into consideration, we must conclude that this method does not help the great majority of students and, consequently, we should eradicate it, or, at least, modify it.

It seems utopia, but it would be an attainable utopia if we prepared text books that helped all our students. If we used a method which could help all our students, we would be creating students who would learn at the maximum of their capacities and all the society could help from that.

\subsection{Methodology}

Not only do students have their preferences and their style of learning but also all the teachers have their own style when working, and that style is also seen when we use the different representational systems. Most of us tend to use a system over the others when we teach. In order to identify what our tendencies are, we need to analyze our way of teaching from the point of view of both the NLP and the Learning Styles. Generally, we will find different types of learning styles in all the groups of students. If our teaching style is the same as that of our students, learning will be easier for them than if it is not the same one, and with a book using all the different styles we would be helping all our students. It is obvious that we cannot choose 
our students and, consequently, the learning styles of our students, but we can choose a teaching method that would suit all our students. In this investigation the methodology of the main publishing houses in English teaching text books has been analyzed (by units and as a whole) in order to see what percentage of quantitative representation they have in the different learning styles corresponding to both theories; Neurolinguistic Programming (NLP) and the Learning Styles theories belonging to Honey and Mumford (Activist, Reflectors, Theorist and Pragmatist) [2].

\subsection{Neurolinguistic Programming}

The VAK model (visual-auditory-kinesthetic), also called Neurolinguistic Programming model, takes into account the neurolinguistic criterion that considers that the input of the information becomes through the eye, ear and body, from which we have the visual, auditory and kinesthetic systems. If, for example, after a school trip we asked a group of students to describe some of the places that they had visited, probably all of them would describe different things, because each one would have paid attention to different things. We do not remember everything that happens, but just part of it. Each representational system has its own characteristics and rules of operation.

To use a system over the others implies that there are systems that are used less often and, therefore, that different representational systems will have different degrees of development. The most often used one is important for two reasons: firstly, because the more we use a representational system, the more developed it will become and secondly, because the representational systems are not neutral since each one has its own characteristics. In the classroom context that means that, after having had the same explanation, all the students will not remember the same information.

For some students, for example, it will be easier to remember the explanations that were written on the blackboard, whereas for others the words of the teacher will be better remembered and, in a third group, we would have students who will remember the assumptions that this class had on them. It is statistically impossible that a teacher has spent exactly the same time explaining the same topic in each one of the different representational systems, though we must try to use a similar number of exercises belonging to different representational systems when we explain something.

To visualize helps us to establish relations between different ideas and concepts. When a student has problems to relate concepts he may be processing information through an auditory or kinesthetic form. Using visual representation helps us to establish connections between different ideas and concepts. They store information in any order and quickly. Their behavior is based on their high organization and observation. The capacity of abstraction and the capacity to plan directly are connected to the visual system. Those two characteristics would explain that the great majority of the university students and, consequently also teachers are visual.

The auditory students learn better when they get the explanations orally and when they can speak and explain that information to another person. They store information using a sequential way, reason why an isolated or disordered question involves a great difficulty to them. The auditory students prefer oral explanations. They have the capacity to express their emotions orally.

When we process the information relating it to our sensations and movements, that is to say, to our body, then we are using the kinesthetic system. The kinesthetic students learn when they make things like, for example, experiments or projects. The kinesthetic students need to move. When they study, they often walk or balance themselves to satisfy that necessity of movement. In the classroom, they will look for any excuse to move.

\section{Learning Styles}

Honey and Mumford laid out the learning styles into four styles, and they stand for the four phases of a 
cyclical process of learning similar to the learning cycle; activists, theorists, reflectors and pragmatists [2].

Activist students learn better with activities that demand a challenge, of relative brevity and immediate result. We must try emotion, drama and crisis with them. They must be announced that a variety of activities will be made and what new things will be learned. They are not to work singly. We would have to avoid that these students had a passive role, analyzed or processed data.

Reflector students learn better observing. They must think before acting. We must remind them continuously that they have all the time they need to make the task. It is important to remember that it bothers them to be the center of an activity.

Theorist students love systems and concepts that mean a challenge for them. The teacher will have to remember these students that they can ask anything, anytime about any doubt they might have. They will also like the teacher to remind them that the activities done in class are good to reach clear goals.

Pragmatist students learn better with useful activities and they match the theory to their immediate necessities when they see the others do something. To these students it is necessary to explain them why something is studied, why it is useful and how they put it into practice. The teacher must remind these students that they are studying something that will be needed in their daily tasks.

\section{Results}

The publishing houses that were included in this research were the prestigious Pearson/Longman, Oxford, Cambridge, Heinemann/Macmillan and Richmond, and as far as the NLP is concerned, we should congratulate the publishing houses. After analyzing different publishing houses belonging to the same level, one of the main common attributes that have been found is the great numerical equality of exercises that could help the different systems of neurolinguistic representations. The general neurolingistic representation in the publishing houses would be; 35\% of Visual, 33\% of Auditory and 32\% of Kinesthetic exercises. The Oxford publishing house turns out to be the one that could help the Visual students more (50\%). Cambridge is second (41.5\%), Pearson is third (38.5\%), whereas Heinemann (24.1\%) and Richmond (20.8\%) include a smaller representation of exercises that could help this group of students. The Visual style is the one that has the greatest representation in three out of five publishing houses, although not by much from the second most frequent used style, the auditory style. The one with the greatest percentage is Heinemann (44.1\%), followed by Richmond (40.8\%) and Cambridge (30.5\%). Those that have a smaller percentage are Oxford (26\%) and Pearson (24.2\%). The Kinesthetic style is the least used in two out of five publishing houses although not by a remarkable big percentage from the other representational systems, and varies between the greatest representation of Richmond (38.4\%) and the representations of Pearson (37.3\%), Heinemann (31.8\%), Cambridge (28\%) and Oxford (24\%). This analysis shows that the books of the most sold and used publishing houses in English teaching are close to be Learning Generators. The percentage of visual children is usually very superior to the auditory and kinesthetic children, for that reason many activities are prepared for these children.

On the contrary, as far as the Learning Styles are concerned, we should criticize the work of the publishing houses. One of the main common characteristics after analyzing the same publishing houses is the great representation of exercises that a particular Learning Style has over other Styles. The average representation in percentages of the Learning Styles would be; $18.4 \%$ of Activists, $49.4 \%$ of Reflectors, $17.8 \%$ of Theorists and $14 \%$ of Pragmatists. The Reflector Style, with a representation of $49.4 \%$, is the Style which all publishing houses help most. This data is common in all the analyzed publishing houses. The Activist Style is second if we consider the average, with an $18.4 \%$ representation, but it has only been the second most recurring Style in three of the five publishing houses. The third most common Style is the Theorist Style, with a $17.8 \%$, which is also the second most seen Style in three of the five analyzed publishing houses. 
The Pragmatist Style, with an average of $14 \%$, has been the least recurrent Style in three of the five publishing houses, and it is, the Style with the smallest representation in general. The Richmond publishing house turns out to be the one that could help the Activist students most (30\%). The Pearson publishing house is second (23\%) and Cambridge and Heinemann are third (17\%), whereas Oxford has the smallest representation of exercises that could help this group of students. The Reflector Style is the one that has the greatest percentage in all the publishing houses, and with a clear advantage in percentage from the second dominant Style. The publishing houses with the highest percentage (56\%) are Oxford, and on the other hand, Heinemann is the one that has the lowest percentage (43\%). As it can be verified, the highest score and the lowest do not distant to a great extent. Heinemann is also the publishing house with the greatest percentage in exercises with Theorist Style (29\%). Oxford is second (22\%). Cambridge (17\%) and Pearson (14\%) are in the following positions and Richmond has the lowest percentage (7\%). The Pragmatist Style is the least recurrent style and varies between Pearson and Heinemann (11\%) and Oxford, Cambridge and Richmond (16\%).

The excessive representation of exercises that could help the Learning Style with less students together with the small representation of exercises that could help the students with other styles clearly show that the text books follow a mistaken tendency. The higher representation of exercises that could help the Reflectors Style verifies that all the publishing houses, without any exception, follow the natural method. The publishing houses do not consider the different Learning Styles of the students, and they are focused on a method that will soon be obsolete because the academic results do not show good results.

After analyzing the main deficiencies, some activities were created so as to deal with the failures of the analyzed text books (schemes, additional material for the teacher.), and verified if the modifications previously mentioned were effective as far as the attainment of the targets offered by each book, using a control group to which these modifications were not applied [7]. The results were highly encouraging since the students with Learning Styles of smaller representation in text books obtained better results than those that did not do the activities, since they belonged to the control group. This proved that the complementary activities that had been prepared to replace the deficiencies of books, adding exercises and activities that could help students from no-Reflectors Learning Style were positive.

To my concern, the academic results of those students with Activist Style are usually much worse than the students with Theorist and Reflector Style, probably due to the insistence of the publishing houses to help them in text books. We can conclude with clear evidence that the publishing houses do not consider the different Learning Styles at the time of programming their books. On the one hand, they do not seem to consider the percentage of representation of the pupils belonging to each Learning Style. But on the other hand, they seem to consider the spread tendency in the different methods of education of the foreign languages, since they are centered in the natural method, leaving aside, for example, grammar explanations that would could help students with Theorist Style. Paradoxically, they do not turn out to be very communicative since they do not include a great variety of communicative exercises, which could help the students from Activist and Pragmatist Style. This must be because the text books are designed considering educative contexts where classes have a large number of students, which makes the accomplishment of these activities difficult. But this investigation has ended up finding the main failure of the tendency in education in second languages; the communicative method fails because it has an excessive use of exercises of a single Style, which is the one used by the smallest number of students (Reflector Style).

After analyzing the learning styles in the text books used to learn English as a second language, changes should be made to improve the quality of books as they only help a small percentage of students. The excessive use of exercises that help the Learning Style with less students and the small representation of 
exercises which help students with other styles shows that text books follow a mistaken tendency. The higher representation of exercises that could help the Reflector Style shows that all the publishing houses, without exception, follows the natural method. The natural method fails because it has an excess of a single Learning Stle, which is the one with the smallest representation among the students (Reflector Style).

\section{Conclusions}

Now it is time for the publishing houses to pay greater attention to the theories on Learning Styles than to the educative tendencies, as the communicative and natural methodologies in foreign languages could not help all the students. Text books are tools that generate learning, and if we bettered them considering the different Learning Styles, we would be creating a Learning Generator: an optimal tool of learning. The diversity of learning styles and the student's different level in a school subject should not be a problem if we used a never-failing learning generator: the digital book [8]. The evolution of the textbook towards the digital book is now in the Spanish classrooms [9]. The new technologies are here to stay due to its countless advantages.

The only possible problem is the lack of teachers' technological command [10]. It seems that the role of the teacher is changing dramatically, since we used to pass knowledge and now we are mere guides [11]. It also seems that the textbook is also evolving and that the paper format will end up being replaced by a digital format book. Everything seems to point that both evolutions will be overlapped and the education classroom will evolve into online education [12]. As the American writer Elbert Hubbard said "The object of teaching a child is to enable him to get along without his teacher". Can we imagine a learning system where all the students learned at their best? What degree of knowledge could those students end up reaching?

\section{References}

[1] Skinner, B. F. (1992). Verbal Behavior. Massachusetts: Copley, ch. 3-4.

[2] Alonso, C., Gallego, D., \& Honey, Y. P. (1997). Psycho-Pedagogical Resources and Instruments. Learning Styles: Diagnostic Procedures and Improvement. Spain: Universidad de Deusto, Ediciones Mensajero., ch. 1.

[3] Damasio, A. R., \& Damasio, Y. H. (1997). Brain and Language: Biological Foundations II. Madrid: UNED, ch. 4.

[4] Dunn, R., \& Dunn, Y. K. (1984). Teaching and individual learning styles. La Enseñanza y el Estilo Individual de Aprendizaje (pp. 34-41). Madrid: Anaya.

[5] Varela, R. (1998). Teaching and Learning Strategies in Second Languages. Madrid: UNED, ch. 1-6.

[6] Kolb, D. (1984). Experiential Learning: Experience as the Source of Learning and Development (pp. 41-45). New Jersey: Prentice Hall.

[7] Gardner, H. (1993). Multiple Intelligences: The Theory in Practice. New York: Basic Books, ch. 1-3.

[8] Bates, A. (2005). Technology, e-Learning and Distance Education. London: Routledge, ch. 3

[9] Vera, C. (2002). New Technologies Applied to the Teaching of Second Languages. Barcelona: Graó, ch. 3-5.

[10] Cuban, L. (2001). Oversold and Underused: Computers in the Classroom (pp. 11-23). Harvard University Press.

[11] Selwyn, N. (2011). Education and Technology: Key Issues and Debates (pp. 4-62). London: Continuum International Publishing Group.

[12] Vez, J. M. (2002). The Second Language Classroom: Threshold for a Cultural Society. Barcelona: Graó, ch. 4. 


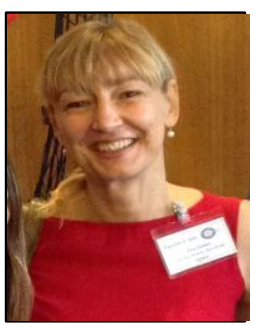

Eva Zanuy has a PhD degree in applied linguistics accredited by Universidad de Educación a Distancia (Spain) in 2008.

She graduated in Anglo-Saxon filology from the University of Barcelona in 1993. She started working in the field of education years before her university graduation. She also graduated in psycho pedagogy from Hofstra University of New York (EEUU) in 1990. At the beginning of 2001 she started working as a teacher in Escoles Betlem, a prestigious private school in Barcelona, and since then she has been coordinating the different teaching and learning grades of English as a second language in students from kindergarten to university levels.

Dr. Zanuy has been involved in many projects, mostly in the field of education and training, including university research, training organizations, schools, research centers etc. operating throughout Europe and Asia. She is also working with some editorials and is about to publish a book on teaching styles, which adapts the Art of War by Sun Tzu for parents and teachers. 